\title{
SEX DIFFERENCES IN RELIABILITY OF TESTS TO ASSESS COGNITIVE FUNCTION
}

\author{
Vaida Berneckè ${ }^{1,2}$, Kazimieras Pukėnas', Marius Brazaitis ${ }^{1}$ \\ Lithuanian Sports University', Kaunas, Lithuania \\ Šiauliai State College ${ }^{2}$, Šiauliai, Lithuania
}

\begin{abstract}
Background. The purpose of this study was to identify whether the learning effect, fatigue, motivation, effort and/or sex-specific neural, physiological and morphological factors influenced the results of the test-retest reliability of tests to assess cognitive function.

Methods. The sample included ten men (age $21.2 \pm 0.4$ years; body mass $79.5 \pm 8.3 \mathrm{~kg}$ ) and ten women (age $22.0 \pm 1$ years; body mass $60.0 \pm 10.0 \mathrm{~kg}$ ). Participants accomplished six tests (three for memory and three for attention) four times, i.e. two times (with 24 hours' break) on successive days (teaching) and two times (with 48 hours' break) on the third and fifth days (re-testing to assess the reliability). The reliability was assessed by calculating the average of the population, standard deviation, and intraclass correlation coefficient (ICC).

Results. In males and females, measurements of attention function were highly reliable over time (ICC > .84 ). The ICCs for volume of spatial memory were above .79 , for memory of even number recognition above .57 for both genders and for memory of figure recognition .00 for males and .79 for females.

Conclusion. In young healthy males and females, measurements of attention function were highly reliable over time. Meanwhile, reliability for volume of spatial memory was good/high for both sexes, but reliability of memory for even number recognition was insufficient for both sexes and results from memory of figure recognition showed good reliability for women and insufficient reliability for men.
\end{abstract}

Keywords: memory, attention, test-retest, reproducibility, gender.

\section{INTRODUCTION}

$\mathrm{N}$ europsychological assessments are designed to measure cognitive functions in both healthy and clinical populations and remain important tools for research studies, clinical diagnoses, patient outcomes, and intervention monitoring (Kueider, Parisi, Gross, \& Rebok, 2012; Zygouris \& Tsolaki, 2014). Why are working memory and attention so important in cognitive control and why are reliability studies of tests assessing cognitive function essential? One reason for this is because the healthy human brain comprises remarkable complexity in both its structural architecture and functional communication networks (Bullmore \& Sporns, 2009). Working memory is critically important in cognition and seems necessary for many cognitive abilities, such as reasoning, language comprehension, planning and spatial processing (D'Esposito, 2007). This system is critical for virtually all forms of "online" cognitive processing, as evidenced by robust correlations with measures of fluid intelligence, scholastic aptitude (Cowan et al., 2005) and is central to much of human behaviour (LaRocque, Lewis-Peacock, Drysdale, Oberauer, \& Postle, 2013). Attention facilitates target processing during both perceptual and post perceptual stages of processing, and functionally dissociated processes have been implicated in the maintenance of different kinds of information in working memory (Awh, Vogel, \& Oh, 2006). Posner and Petersen (1990) have proposed that the sources of attention form a specific system of anatomical areas, which 
can be further broken down into three networks. These networks carry out the functions of alerting, orienting, and executive control (Fan, McCandliss, Sommer, Raz, \& Posner, 2002). Thus, although it is clear that these processes are closely intertwined, the nature of these interactions depends upon the specific variety of attention or working memory that is considered (Awh, Vogel, \& Oh, 2006). In psychological research, cognitive complexity often is used to refer to high-level cognitive processes mainly problem solving, reasoning, and decision making - and their interaction with more basic processes such as perception, learning, motivation, and emotion (Knauff \& Wolf, 2010; Osman, 2010). As Knauff and Wolf (2010) pointed out, there is a second important aspect to complexity - the complexity given by the environment with which the agent has to interact (Osman, 2010). The flexibility and adaptiveness of a cognitive system depends highly on its ability to learn from previous experience (Schmid, Ragni, Gonzalez, \& Funke, 2011). Elements relevant to the solution process are large (complexity), highly interconnected (connectivity), and dynamically changing over time (dynamics). Extensive empirical research has demonstrated that performance varies in systematic ways over time as a result of biological variability, time awake, time on task, circadian rhythms, learning effect and a variety of other factors that impact the effectiveness and efficiency of cognitive processing and are all factors that can affect data between and within trials (Weir, 2005).

There are other ways in which test-retest reliability can be defeated: examiners can fall short through lack of competence (Bauer et al., 2012). Moreover, subjects may show up for an assessment session without adequate reading glasses, or having taken cold medication that affects their alertness (Kipps \& Hodges, 2005), be suffering from a severe headache or illness, the effects of motivation also might play a role in the performance (Barr, 2003). It appears that even in healthy volunteers the learning trajectories may differ by neuropsychological domain, age and education of participants (Beglinger et al., 2005). For the all aforementioned reasons, in the present research we chose a short, simple test that does not necessitate the use of expert examiners, participants were young, healthy, and had the same educational level and accomplished two training sessions before reliability assessment with $48 \mathrm{~h}$ between test-retest sessions. Also, tests were conducted in a low traffic, quiet environment to enable the participant to concentrate solely on the assessment and not be distracted by the surroundings. For reliability analysis, we selected from "Effecton" studio (2006) three attention (the test for the assessment of complex reaction, test for the search of visual objects, the test for attention transfer) and three memory tests (the test for the volume of spatial memory, test for even number recognition, test for figure recognition) that comprehensively assess main characteristics of attention and WM described above.

Another reason justifying the need for repeatability experiments are gender-related brain anatomical (Allen, Damasio, Grabowski, Bruss \& Zhang, 2003; Gur, Gunning-Dixon, Bilker, \& Gur, 2002; Shikhman, 2007), functional differences (Speck et al., 2000), as well as among other differences circulating gonadal hormones have impact on cognition (Gur et al., 2000; Mathew, Wilson, \& Tant, 1986). The literature has addressed numerous findings that support several brain anatomical, gender-related brain differences, such as males tend to have larger brain volume, while the gray-to-white ratio tends to be grater in females (Allen et al., 2003; Gur et al., 2002; Shikhman, 2007), also males having a significantly larger left versus right planum temporale area, a difference that is not significant in females (Kulynych, Vladar, Jones, \& Weinberger, 1994). A larger splenium in females versus a larger genu in males is one aspect of the gender-related differences in the dimensions of the corpus callosum (Dubb, Gur, Avants, \& Gee, 2003) and hippocampal volumetric sex-differences (Maller, Réglade-Meslin, Anstey, $\&$ Sachdev, 2006). Both post-mortem and imaging studies have found that relative to brain size, women have larger volumes in the hippocampus (Filipek, Richelme, Kennedy, \& Caviness, 1994), caudate nucleus (Filipek et al., 1994; Murphy et al., 1996), anterior cingulate gyrus (Paus et al., 1996) dorsolateral prefrontal cortex and planum temporale (Schlaepfer et al., 1995). In contrast, the relative volumes of the amygdala (Giedd et al., 1996) and paracingulate gyrus (Paus et al., 1996) are consistently larger in men (Andreano \& Cahill, 2009). From a neuroimaging perspective, Filippi et al. (2013) research has shown that there are gender differences in functional connectivity during resting state; i.e. the authors found that women had greater intrinsic functional connectivity inclusive of the cingulate, dorsolateral prefrontal 
cortex, and the inferior frontal gyrus, while men demonstrated increased functional connectivity in parietal regions, characteristics that the authors attribute to potential strategy differentiation. These observed differences could help explain the disparity in performance between the genders on various cognitive tasks, as well as bringing into question the possibility of inherent neural network differences (Hill, Laird, \& Robinson, 2014).

The above-described facts suggest that the disparity in performance between the genders in various cognitive tasks is evident, as well as bringing into question whether the possibility of distinct consistency in test-retest reliability between the genders exists. According to the evidence, women are more likely than men to show significantly greater activations in the prefrontal regions (Goldstein et al., 2005), which have been implicated in encoding and retrieval of visuospatial information (Carter et al., 1998; Mayberg, 1997; Poldrack et al., 1999; Smith \& Jonides, 1999; Wagner, 1999). Moreover, the availability of dopamine transporters (Lavalaye, Booij, Reneman, Habraken, \& van Royen, 2000; L. H. Mozley, R. C. Gur, P. D. Mozley, \& R. E. Gur, 2001; Staley et al., 2001) and plasma serotonin levels are also higher in women than in men (Ortiz, Artigas, \& Gelpi, 1988) when estrogens and dopamine enhance working memory (Berman et al., 1997; Jacobs \& D'Esposito, 2011; Shaywitz et al., 1999) and estradiol increases emotional arousal (O’Neal, Means, Poole, \& Hamm, 1996). Besides, Barral and Debu (2004) suggest that while males are faster than female at aiming at a target, the females are more accurate. Regarding to reviewed literature about neurobiological sex differences relevant to attention and memory, we hypothesize that higher reliability will be expected for women than for men.

\section{METHODS}

Experimental approach to the problem. The experiment was designed aiming at assessing the reliability of tests of cognitive functions (memory and attention) depending on gender. The functions of memory and attention were measured by the same examiner over four days, the research participants accomplished two familiarization sessions with 24 hours break and two sessions for test-retest reliability with 48 hours break. Our aim was to identify whether the learning effect, fatigue, motivation, effort and/or sex-specific neural, physiological and morphological factors influenced the results of the test-retest sessions.
The dependent variables included measures of short term memory: memorization, storage and recall; for attention: stability, concentration, distribution and transfer. The independent variables were the two identical trials (three standard memory and three attention tests) over two days and sex group (women vs men).

Organization and procedure of the research. The research was conducted in the Sports Science and Innovation Institute at Lithuanian Sports University. The research participants were introduced to the aims, procedure and possible inconveniences of the research. Young and healthy students of Lithuanian Sports University: ten men (age $21.2 \pm 0.4$ years; body mass $79.5 \pm 8.3 \mathrm{~kg}$; stature $184 \pm 4.3 \mathrm{~cm}$; BMI $23.5 \pm$ $2.4 \mathrm{~kg} / \mathrm{m}^{2}$; fat free mass $65.8 \pm 5.4 \mathrm{~kg}$; mean $\pm \mathrm{SD}$ ) and ten women (age $22.0 \pm 1$ years; body mass $60.0 \pm 10.0 \mathrm{~kg}$; stature $168.0 \pm 6.0 \mathrm{~cm}$; BMI $21.0 \pm$ $2 \mathrm{~kg} / \mathrm{m}^{2}$; fat free mass $44.0 \pm 5.0 \mathrm{~kg}$; mean $\pm \mathrm{SD}$ ) participated in the research. They accomplished the tests four times, i.e. two times (with 24 hours' break) on successive days (teaching) and two times (with 48 hours' break) on the third and fifth days (re-testing to assess the reliability). The research participants had to complete six tests (three tests for memory and three for attention); the tests were presented in random order. The accomplishment of all tests lasted approximately for 20 minutes. The participants completed the tests in a quiet environment: they were not disturbed by other people, noise, music or other distracters. The tests of the memory and attention were described elsewhere (Bernecke et al., 2012).

Statistical analysis. The reliability of research results was assessed by calculating the average of the population, standard deviation, and intraclass correlation coefficient (ICC). The ICCs were used to analyse the correlations between the values obtained on different days (Singh et al., 2011). The ICC was computed as a single-measure ICC using a two-way random-effect model (absolute agreement). The level of significance was set at $p<.05$. Statistical analyses were performed using IBM SPSS Statistics software (v. 22; IBM Corporation, Armonk, NY).

\section{RESULTS}

Reliability assessment of memory tests related to gender. The data from two test-retest sessions for all three memory tests in male and female subjects are presented in Table 1. The results of the average length of number sequence in testing the volume 
of spatial memory showed good reiteration of the results for both genders. The results of the intraclass correlation coefficient of the average number of guessed symbols of testing the amount of numbers memorization showed high reliability for males and good reliability for females. The results of testing even number recognition revealed poor reliability for both genders. The results of testing memory for figure recognition demonstrated good reliability for the females, whereas insufficient reliability has been found for males, in addition, females recognized significantly greater number of figures than males (Table 1).
Reliability assessment of attention tests related to gender. The data from two test-retest sessions for all three attention tests in males and females are presented in Table 2. The results of the test of complex reaction assessment showed high reliability for both genders. The results of testing the search for image samples revealed high reliability for males and females; besides, males were significantly faster in task accomplishment compared with the females. The results of assessing the reliability of testing attention transfer revealed high reliability for females and good reliability for males (Table 2).

Table 1. Results of the reliability assessment of memory tests for both genders

\begin{tabular}{|c|c|c|c|c|c|c|c|c|}
\hline \multirow{3}{*}{$\begin{array}{l}\text { Gender/ } \\
\text { ICC }\end{array}$} & \multicolumn{4}{|c|}{ Volume of spatial memory } & \multirow{2}{*}{\multicolumn{2}{|c|}{$\begin{array}{c}\begin{array}{c}\text { Memory for even number } \\
\text { recognition }\end{array} \\
\begin{array}{c}\text { Number of correct } \\
\text { answers }\end{array}\end{array}$}} & \multirow{2}{*}{\multicolumn{2}{|c|}{$\begin{array}{c}\begin{array}{c}\text { Memory for figure } \\
\text { recognition }\end{array} \\
\begin{array}{c}\text { Number of correctly } \\
\text { recognized figures }\end{array}\end{array}$}} \\
\hline & \multicolumn{2}{|c|}{$\begin{array}{c}\text { Average length of numeric } \\
\text { sequence }\end{array}$} & \multicolumn{2}{|c|}{$\begin{array}{c}\text { Average number of guessed } \\
\text { symbols }\end{array}$} & & & & \\
\hline & Test & Re-test & Test & Re-test & Test & Re-test & Test & Re-test \\
\hline Male & $7.00 \pm 0.72$ & $6.79 \pm 0.66$ & $6.77 \pm 0.73$ & $6.51 \pm 0.69$ & $10.5 \pm 2.22$ & $10.6 \pm 2.95$ & $7.5 \pm 0.53 *$ & $7.2 \pm 1.23 *$ \\
\hline$I C C^{6}$ & \multicolumn{2}{|c|}{$.87^{\#}$} & \multicolumn{2}{|c|}{$.91^{\#}$} & \multicolumn{2}{|c|}{.57} & \multicolumn{2}{|c|}{.00} \\
\hline Female & $6.52 \pm 0.75$ & $6.68 \pm 0.56$ & $6.3 \pm 0.68$ & $6.46 \pm 0.6$ & $11.14 \pm 2.32$ & $12.07 \pm 2.7$ & $8.4 \pm 0.70$ & $8.2 \pm 0.42$ \\
\hline$I C C^{\prime 6}$ & \multicolumn{2}{|c|}{$.79^{\#}$} & \multicolumn{2}{|c|}{$.82^{\#}$} & \multicolumn{2}{|c|}{$.68^{\#}$} & \multicolumn{2}{|c|}{$.79^{\#}$} \\
\hline
\end{tabular}

Notes. Values are shown as mean and standard deviation. $I C C^{\prime}-$ intraclass correlation coefficient for males. ICC ${ }^{\prime}-$ intraclass correlation coefficient for females. ${ }^{*} p<.05$, compared with female. ${ }^{*}$ significant, $p<.05$.

Table 2. Results of the reliability assessment of attention tests for both genders

\begin{tabular}{|c|c|c|c|c|c|c|}
\hline \multirow{3}{*}{$\begin{array}{l}\text { Gender/ } \\
\text { ICC }\end{array}$} & \multirow{2}{*}{\multicolumn{2}{|c|}{$\begin{array}{c}\text { Test of complex reaction } \\
\begin{array}{c}\text { Time of reaction } \\
(\mathrm{ms})\end{array} \\
\end{array}$}} & \multirow{2}{*}{\multicolumn{2}{|c|}{$\begin{array}{c}\text { Test of search for image samples } \\
\begin{array}{c}\text { Average time of the accomplishment } \\
\text { of five tasks (s) }\end{array}\end{array}$}} & \multirow{2}{*}{\multicolumn{2}{|c|}{$\begin{array}{c}\text { Test for attention transfer } \\
\begin{array}{c}\text { Speed of accomplishing } \\
\text { the task (s) }\end{array} \\
\end{array}$}} \\
\hline & & & & & & \\
\hline & Test & Re-test & Test & Re-test & Test & Re-test \\
\hline Male & $598.56 \pm 44.66$ & $585.6 \pm 51.98$ & $36.6 \pm 6.93^{*}$ & $36.4 \pm 6.11^{*}$ & $179.0 \pm 40.73$ & $165.2 \pm 33.64$ \\
\hline$I C C^{6}$ & \multicolumn{2}{|c|}{$.93^{\#}$} & \multicolumn{2}{|c|}{$.97^{\#}$} & \multicolumn{2}{|c|}{$.84^{\#}$} \\
\hline Female & $600.21 \pm 57.09$ & $609.29 \pm 64.0$ & $29.20 \pm 5.53$ & $30.00 \pm 5.62$ & $167.14 \pm 45.32$ & $168.71 \pm 41.67$ \\
\hline$I C C^{\prime \prime}$ & \multicolumn{2}{|c|}{$.93^{\#}$} & \multicolumn{2}{|c|}{$.96^{\#}$} & \multicolumn{2}{|c|}{$.94^{\#}$} \\
\hline
\end{tabular}

Notes. Values are shown as mean and standard deviation. $I C C^{\prime}$ - intraclass correlation coefficient for male. $I C C^{\prime \prime}$ - intraclass correlation coefficient for female. ${ }^{*} p<.05$, compared with females. ${ }^{*}$ significant, $p<.01$.

\section{DISCUSSION}

Our study focused on sex-specific test-retest reliability of responses to tests assessing memory and attention. The tests of memory and attention were found to be stable over a 48-hourperiod for both genders with one exception for figure recognition memory for the males. In the present study the two familiarization sessions were accomplished with 24 hour brake. Two training sessions were chosen because many authors affirmed that the most prominent learning effect occurs between the first and second test-retest sessions. As Falleti, Maruff, Collie, and Darby's (2006) study illustrated that 
performance generally improved from the first to the second assessment on the CogState battery. Moreover, after the second assessment, the performance of the group stabilized and improved no further on any of the cognitive measures (Falleti et al., 2006). Meanwhile, Claus, Mohr, and Chase (1991) demonstrated improvement across three weekly test sessions in which alternate forms were used. Also, Benedetto et al. (1995) demonstrated minimal learning after three trials across six tests from the ANAM library. According to Beglinger et al. (2005), the dual baseline may be beneficial with two to three practice sessions before a treatment is measured. The results from our study have confirmed that two training sessions are sufficient to achieve good test repeatability for both genders.

The length of test-retest interval is another important factor to consider (Barr, 2003). One must contemplate the additional range of factors influencing the comparability of test settings at baseline and retesting (Barr, 2003). There are several benefits in investigating changes in performance over very short test-retest intervals (Falleti et al., 2006). First, estimates of the magnitude of practice can be derived under conditions most optimal for improvement to occur (Falleti et al., 2006). Second, the use of very short intervals minimizes the extent to which the individuals will undergo any physical or psychological changes that could give rise to true cognitive change (i.e., changes in sleep patterns, stage in menstrual cycle) (Falleti et al., 2006). Therefore, estimates of improvement in these conditions would be more likely to reflect only measurement-related factors and not include any effects of normal biological variability that are known to cause subtle changes in cognition and which operate over weeks or months (Bland \& Altman, 1996). For the above discussed reasons in this study we have chosen the 24-hour break between test-retest sessions for teaching and 48hour break for reliability experiment. Results of this inter-day reliability study showed a high stability between sessions for the attention in both genders $(I C C>.93)$ with one exception for test of attention transfer for male $(I C C=.84)$. Similar results were found in our previous intra-day experiment (Bernecke et al., 2012) where $I C C$ values ranged from good to high $(I C C>$.86). The results from our inter-day and intra-day experiments showed good/ high stability for volume of spatial memory test. Meanwhile, insufficient reliability was obtained for memory of even number recognition (inter-day experiment) and for figure recognition during both inter-day and intra-day experiments.

Observed differences between males' and females' brain anatomical and functional characteristics could help explain the disparity in performance between the genders on various cognitive tasks (Hill et al., 2014). In general, the gender-related differences include a wide range of processing skills (González-Garrido, GómezVelázquez, Sequeira, Ramos-Loyo, \& LópezFranco, 2013). It has been shown that females recall better the appearance of others better than males (Mast \& Hall, 2006) and score higher on tasks involving manipulation of phonological and semantic information, episodic and semantic memory, verbal learning, verbal analytical working memory (WM), object location memory, fine motor skills, perceptual speed and writing skills (Hedges \& Nowell, 1995). Our results support the proposition that women better recall than men, we established that women significantly better performed figure recognition task. Moreover, good stability for the test-retest results were established for the women $(I C C=.79)$ and unstable for men (ICC $=.00)$. In general, women were more likely than men to show significantly greater activations in the hypothesized prefrontal regions, despite the same performance as the men (Goldstein et al., 2005). These regions included middle, inferior, and orbital prefrontal regions, which have been implicated in encoding and retrieval of visuospatial, semantic, and phonological information and inhibitory functions associated with orbitofrontal cortex (Botvinick, Nystrom, Fissell, Carter, \& Cohen, 1999; Carter et al., 1998; Mayberg, 1997; Poldrack et al., 1999; Smith \& Jonides, 1999; Wagner, 1999). While males tend to score higher on tasks involving mathematical (Lynn \& Irwing, 2008), spatial (Kaufman, 2007; Lejbak, Crossley, \& Vrbancic, 2011), object (Lejbak et al., 2011), visuospatial working memory (VSWM), fluid reasoning, and positional reconstruction, or when spatiotemporal analyses are required (Lejbak, Vrbancic, \& Crossley 2009; Ramos-Loyo \& Sánchez-Loyo, 2011). In rodents, exogenous estradiol can enhance the consolidation of object recognition (Luine, Jacome, \& Maclusky, 2003), water maze navigation (Packard \& Teather, 1997), and inhibitory avoidance (Rhodes \& Frye, 2004). However, we have not found any significant differences between genders for volume of spatial memory or for even number recognition. Repeatability for the volume 
of spatial memory was good/high for the men and good for the women, repeatability for memory of even number recognition was insufficient for both genders. Many authors have established that males have faster reaction times than females and female disadvantage is not reduced by practice (Adam et al., 1999; Dane \& Erzurumlugoglu, 2003). In the present study, test of search for image samples best reflects the reaction because there is minimum probability for the mistake and can be performed easily and fast. However, the results of the aforementioned test showed faster reaction time for the female subjects compared to the male ones $(p<.05)$; the reliability results were high for both genders $(I C C>.96)$. Obviously, females were faster because during this test they had to find the numbers quickly and we believe that this was the case because it has been established that females are more accurate (Barral \& Debu, 2004) and have a better object location memory than males (Hedges \& Nowell, 1995). In our case women showed better test-retest reliability $(I C C=.94)$ then men $(I C C=.84)$ for test of attention transfer, the test timing does not differ significantly between genders. Equal high reliability have been found between genders $(I C C=.93)$ for the test of complex reaction and also the test timing does not differ significantly.

\section{CONCLUSION}

In conclusion, in young healthy males and females, measurements of attention function, such as tests of complex reaction, search for image samples and attention transfer are highly reliable over time. Whereas reliability for volume of spatial memory are good/high for both genders, reliability of memory for even number recognition is insufficient for both genders, and results from memory of figure recognition showed good reliability for females and insufficient reliability for men.

\section{REFERENCES}

Adam, J. J., Paas, F. G., Buekers, M. J., Wuyts, I. J., Spijkers, W. A., \& Wallmeyer, P. (1999). Gender differences in choice reaction time: Evidence for differential strategies. Ergonomics, 42(2), 327-335.

Allen, J. S., Damasio, H., Grabowski, T. J., Bruss J., \& Zhang, W. (2003). Sexual dimorphism and asymmetries in the gray-white composition of the human cerebrum. Neuroimage, 18(4), 880-894.

Andreano, J. M., \& Cahill, L. (2009). Sex influences on the neurobiology of learning and memory. Learning \& Memory, 16(4), 248-266. doi: 10.1101/1m.918309

Awh, E., Vogel, E. K., \& Oh, S. H. (2006). Interactions between attention and working memory. The Journal of Neuroscience, 139(1), 201-208.

Barr, W. B. (2003). Neuropsychological testing of high school athletes. Preliminary norms and test-retest indices. Archives of Clinical Neuropsychology, 18(1), 91-101. doi: 10.1016/S0887-6177(01)00185-8

Barral, J., \& Debu, B. (2004). Aiming in adults: Sex and laterality effects. Laterality, 9(3), 299-312.

Bauer, R. M., Iverson, G. L., Cernich, A. N., Binder, L. M., Ruff, R. M., \& Naugle, R. I. (2012). Computerized neuropsychological assessment devices: joint position paper of the American Academy of Clinical Neuropsychology and the National Academy of Neuropsychology. The Clinical Neuropsychologist, 26(2), 177-196. doi: 10.1093/arclin/acs027

Beglinger, L. J., Gaydos, B., Tangphao-Daniels, O., Duff, K., Kareken, D. A., ... Siemers, E. R. (2005).
Practice effects and the use of alternate forms in serial neuropsychological testing. Archives of Clinical Neuropsychology, 20(4), 517-529.

Benedetto, J. M., Harris, W. C., \& Goernert, P. N. (1995). Automated Neuropsychological Assessment Metrics (ANAM) repeated assessment stability (No. ERPL 95-02). Mankato, MN: Engineering Psychology and Human Performance Laboratory.

Berman, K. F., Schmidt, P. J., Rubinow, D. R., Danaceau, M. A., Van Horn, J. D., ... Weinberger, D. R. (1997). Modulation of cognition-specific cortical activity by gonadal steroids: A positron-emission tomography study in women. Proceedings of the National Academy of Sciences, USA, 94(16), 8836-8841.

Bernecke, V., Eimantas, N., Paulauskas, H., Skaisgiryte, B., Kudrevicius, J., \& Brazaitis, M. (2012). Assessment of the Reliability of Cognitive (attention and memory) tests. Education. Physical Training. Sport, 3(86), 18-25.

Bland, J. M., \& Altman, D. G. (2003). Applying the right statistics: Analyses of measurement studies. Ultrasound in Obstetrics and Gynecology, 22(1), 85-93.

Botvinick, M., Nystrom, L. E., Fissell, K., Carter, C. S., \& Cohen, J. D. (1999). Conflict monitoring versus selection-for-action in anterior cingulate cortex. Nature, 402(6758), 179-181.

Bullmore, E., \& Sporns, O. (2009). Complex brain networks: Graph theoretical analysis of structural and 
functional systems. Nature Reviews Neuroscience, 10(3), 186-198. doi: 10.1038/nrn2575

Carter, C., Braver, T. S., Barch, D. M., Botvinick, M. M., Noll, D., \& Cohen, J. D. (1998). Anterior cingulate cortex, error detection, and the online monitoring of performance. Science, 280(5364), 747-749.

Claus, J., Mohr, E., \& Chase T., (1991). Clinical trials in dementia: Learning effects with repeated testing. Journal of Psychiatry \& Neuroscience, 16(1), 1-4.

Cowan, N., Elliott, E. M., Saults, J. S., Morey, C. C., Mattox, S., Hismjatullina, A., Conway, A. R. (2005). On the capacity of attention: Its estimation and its role in working memory and cognitive aptitudes. Cognitive Psychology, 51(1), 42-100.

D’Esposito, M. (2007). From cognitive to neural models of working memory. Philosophical Transactions of the Royal Society B: Biological Sciences, 362(1481), 761-772.

Dane, S., \& Erzurumluoglu, A. (2003). Sex and handedness differences in eye-hand visual reaction times in handball players. International Journal of Neuroscience, 113(7), 923-929.

Der, G., \& Deary, I. J. (2006). Age and sex differences in reaction time in adulthood: Results from the United Kingdom health and lifestyle survey. Psychology and Aging, 21(1), 62-73.

Dubb, A., Gur, R., Avants, B., \& Gee, J. (2003). Characterization of sexual dimorphism in the human corpus callosum. Neuroimage, 20(1), 512-519.

Falleti, M. G., Maruff, P., Collie, A., \& Darby, D. G. (2006). Practice effects associated with the repeated assessment of cognitive function using the CogState battery at 10-minute, one week and one month testretest intervals. Journal of Clinical and Experimental Neuropsychology, 28(7), 1095-1112.

Fan, J., McCandliss, B. D., Sommer, T., Raz, A., \& Posner, M. I. (2002). Testing the efficiency and independence of attentional networks. Journal of Cognitive Neuroscience, 14(3), 340-347.

Filipek, P. A., Richelme, C., Kennedy, D. N., \& Caviness, V. S. Jr. (1994). The young adult human brain: An MRI-based morphometric analysis. Cerebral Cortex, 4(4), 344-360.

Filippi, M., Valsasina, P., Misci, P., Falini, A., Comi, G., \& Rocca, M. A. (2013). The organization of intrinsic brain activity differs between genders: A resting-state fMRI study in a large cohort of young healthy subjects. Human Brain Mapping, 34(6), 1330-1343. doi: 10.1002/ hbm. 21514

Giedd, J. N., Vaituzis, A. C., Hamburger, S. D., Lange, N., Rajapakse, J. C., Kaysen, D., ... Rapoport, J. L. (1996). Quantitative MRI of the temporal lobe, amygdala, and hippocampus in normal human development: Ages 4-18 years. Journal of Comparative Neurology, 366(2), 223230. doi: 10.1002/(SICI)1096-9861(19960304)3

Goldstein. J. M., Jerram, M., Poldrack, R., Anagnoson, R., Breiter, H. C., Makris, N., ... \& Seidman, L. J. (2005).
Sex differences in prefrontal cortical brain activity during fMRI of auditory verbal working memory. Neuropsychology, 19(4), 509-519. doi: 10.1037/08944105.19.4.509

González-Garrido, A. A., Gómez-Velázquez, F. R., Sequeira, H., Ramos-Loyo, J., \& López-Franco., A. L. (2013). Gender differences in visuospatial working memory - does emotion matter? International Journal of Psychological Studies, 5(1), 11-21. doi: http://dx.doi. org/10.5539/ijps.v5n1p11

Gur, R. C., Alsop, D., Glahn, D., Petty, R., Swanson, C. L., Maldjian, J. A., Turetsky, B. I., ... Gur, R. E. (2000). An fMRI study of sex differences in regional activation to a verbal and a spatial task. Brain and Language, 74(2), 157-170.

Gur, R. C., Gunning-Dixon, F. Bilker, W. B., \& Gur, R. E. (2002). Sex differences in temporo-limbic and frontal brain volumes of healthy adults. Cerebral Cortex, 12(9), 998-1003. doi: 10.1093/cercor/12.9.998

Hedges, L. V., \& Nowell, A. (1995). Sex differences in mental scores, variability, and numbers of high-scoring individuals. Science, 269(5220), 41-45.

Hill, A. C., Laird, A. R., \& Robinson, J. L. (2014). Gender differences in working memory networks: A BrainMap meta-analysis. Biological Psychology, 102, 18-29. doi: 10.1016/j.biopsycho.2014.06.008

Jacobs, E., \& D’Esposito, M. (2011). Estrogen shapes dopamine-dependent cognitive processes: implications for women's health. The Journal of Neuroscience, 31(14), 5286-5293.

Kaufman, S. B. (2007). Sex differences in mental rotation and spatial visualizationability: Can they be accounted for by differences in working memory capacity? Intelligence, 35(3), 211-223. doi: 10.1016/j. intell.2006.07.009

Kipps, C., \& Hodges, J. (2005). Cognitive Assessment For Clinicians. Journal of Neurology, Neurosurgery, and Psychiatry, 76(Suppl. 1), i22-i30. doi: 10.1136/ jnnp.2004.059758

Knauff, M., \& Wolf, A. G. (2010). Complex cognition: The science of human reasoning, problem-solving, and decision-making. Cognitive Processing, 11(2), 99-102. doi: 10.1007/s10339-010-0362-z

Kueider, A. M., Parisi, J. M., Gross, A. L., \& Rebok, G. W. (2012). Computerized cognitive training with older adults: a systematic review. PLoS ONE, 7(7), e40588. doi: 10.1371/journal.pone.0040588.

Kulynych, J. J., Vladar, K., Jones, D. W., \& Weinberger, D. R. (1994). Gender differences in the normal lateralization of the supratemporal cortex: MRI surface-rendering morphometry of Heschl's gyrus and the planum temporale. Cerebral Cortex, 4(2), 107-118.

LaRocque, J. J., Lewis-Peacock, J. A., Drysdale, A. T., Oberauer, K., \& Postle, B. R. (2013). Decoding attended information in short-term memory: An EEG study. Journal of Cognitive Neuroscience, 25(1), 127-142. doi: 10.1162/jocn_a_00305 
Lavalaye, J., Booij, J., Reneman, L., Habraken, J. B., \& van Royen, E. A. (2000). Effect of age and gender on dopamine transporter imaging with [ ${ }^{123}$ I] FP-CIJ SPET in healthy volunteers. Schizophrenia Research, 27(7), 867-869.

Lejbak, L., Crossley, M., \& Vrbancic, M. (2011). A male advantage for spatial and objectbut not verbal working memory using the n-back task. Brain and Cognition, 76(1), 191-196. doi: 10.1016/j.bandc.2010.12.002

Lejbak, L., Vrbancic, M., \& Crossley, M. (2009). The female advantage in object location memory is robust to verbalizability and mode of presentation of test stimuli. Brain and Cognition, 69(1), 148-153. doi: 10.1016/j. bandc.2008.06.006

Luine, V. N., Jacome, L. F., \& Maclusky, N. J. (2003). Rapid enhancement of visual and place memory by estrogens in rats. Endocrinology, 144(7), 2836-2844.

Lynn, R., \& Irwing, P. (2008). Sex differences in mental arithmetic, digit span, and $g$ defined as working memory capacity. Intelligence, 36(3), 226-235.

Maller, J. J., Réglade-Meslin, C., Anstey, K. J., \& Sachdev, P. (2006). Sex and symmetry differences in hippocampal volumetrics: Before and beyond the opening of the crus of the fornix. Hippocampus, 16(1), 80-90. doi: 10.1002/hipo.20133

Mast, M. S., \& Hall, J. A. (2006). Women's advantage at remembering others' appearance: A systematic look at the why and when of a gender difference. Personality \& Social Psychology Bulletin, 32(3), 353-364. doi: 10.1177/0146167205282150

Mathew, R. J., Wilson, W. H., \& Tant, S. R. (1986). Determinants of resting regional cerebral blood flow in normal subjects. Biological Psychiatry, 21(10), 907-914. Mayberg, H. S. (1997). Limbic-cortical dysregulation: A proposed model of depression. Journal of Neuropsychiatry and Clinical Neurosciences, 9(3), 471-481.

Mozley, L. H., Gur, R. C., Mozley, P. D., \& Gur, R. E. (2001). Striatal dopamine transporters and cognitive functioning in healthy men and women. The American Journal of Psychiatry, 158(9), 1492-1499.

Murphy, D. G., DeCarli, C., McIntosh, A. R., Daly, E., Mentis, M. J., Pietrini, P., ... Rapoport, S. I. (1996). Sex differences in human brain morphometry and metabolism: An in vivo quantitative magnetic resonance imaging and positron emission tomography study on the effect of aging. Archives of General Psychiatry Journal, 53(7), 585-594.

O’Neal, M. F., Means, L. W., Poole, M. C., \& Hamm, R. J. (1996). Estrogen affects performance of ovariectomized rats in a two-choice water-escape working memory task. Psychoneuroendocrinology, 21(1), 51-65.

Ortiz, J., Artigas, F., \& Gelpi, E. (1988). Serotonergic status in human blood. Life Sciences, 43(12), 983-990.

Osman, M. (2010). Controlling uncertainty: A review of human behavior in complex dynamic environments. Psychological Bulletin, 136(1), 65-86.
Packard, M. G., \& Teather, L. A. (1997). Post-training estradiol injections enhance memory in ovariectomized rats: Cholinergic blockade and synergism. Neurobiology of Learning and Memory, 68(2), 172-188.

Paus, T., Otaky, N., Caramanos, Z., MacDonald, D., Zijdenbos, A., D'Avirro, D., ... Evans, A. C. (1996). In vivo morphometry of the intrasulcal gray matter in the human cingulate, paracingulate, and superior-rostral sulci: Hemispheric asymmetries, gender differences and probability maps. Journal of Comparative Neurology, 376(4), 664-673.

Poldrack, R. A., Wagner, A. D., Prull, M. W., Desmond, J. E., Glover, G. H., \& Gabrieli, J. D. (1999). Functional specialization for semantic and phonological processing in the left inferior prefrontal cortex. Neuroimage, 10(1), 15-35.

Posner, M. I., \& Petersen, S. E. (1990). The attention system of the human brain. Annual Review of Neuroscience, 13, 25-42.

Ramos-Loyo, J., \& Sanchez-Loyo, L. M. (2011). Gender differences in EEG coherent activity before and after training navigation skills in virtual environments. Fiziologiia Cheloveka, 37(6), 68-75.

Rhodes, M. E., \& Frye, C. A. (2004). Estrogen has mnemonic-enhancing effects in the inhibitory avoidance task. Pharmacology Biochemistry and Behavior, 78(3), 551-558.

Schlaepfer, T. E., Harris, G. J., Tien, A. Y., Peng, L., Lee, S., \& Pearlson, G. D. (1995). Structural differences in the cerebral cortex of healthy female and male subjects: A magnetic resonance imaging study. Psychiatry Research, 61(3), 129-135.

Schmid, U., Ragni, M., Gonzalez, C., \& Funke, J. (2011). The challenge of complexity for cognitive systems. Cognitive Systems Research, 12(3-4), 211-218. doi: 10.1016.j.cogsys.2010.12.007

Shaywitz, S. E., Bennett, A., Pugh, K. R., Fulbright, R. K., Skudlarksi, P., Mencl, W. E., et al. (1999). Effect of estrogen on brain activation patterns in postmenopausal women during working memory tasks. Journal of the American Medical Association, 281(13), 1197-1202.

Shikhman, M. (2007). Age, gender, general intelligence and educational level influences on working memory. 1st Edition. City University of New York, USA. ISBN-10: 0549267816.

Singh, A. S., Vik, F. N., Chinapaw, M. J., Uijtdewilligen, L., Verloigne, M., Fernández-Alvira, J. M., ... Brug, J. (2011). Test-retest reliability and construct validity of the ENERGY-child questionnaire on energy balancerelated behaviours and their potential determinants: the ENERGY-project. International Journal of Behavioral Nutrition and Physical Activity, 8, 136. doi: 10.1186/14795868-8-136.

Smith, E. E., \& Jonides, J. (1999). Storage and executive processes in the frontal lobes. Science, 283(5408), 1657-1661. 
Speck, O., Ernst, T., Braun, J., Koch, C., Miller, E., \& Chang, L. (2000). Gender differencesin the functional organization of the brain for working memory. NeuroReport, 11(11), 2581-2585.

Staley, J. K., Krishnan-Sarin, S., Zoghbi, S., Tamagnan, G., Fujita, M., Seibyl, J. P., Maciejewski, P. K., O'Malley, S., \& Innis, R. B. (2001). Sex differences in $\left.{ }^{123} \mathrm{I}\right]$ beta-CIT SPECT measures of dopamine and serotonin transporter availability in healthy smokers and nonsmokers. Synapse, 41(4), 275-284.
Wagner, A. D. (1999). Working memory contributions to human learning and remembering. Neuron, 22(1), 19-22.

Weir, J. P. (2005). Quantifying test-retest reliability using the Intraclass Correlation Coefficient and the SEM. The Journal of Strength \& Conditioning Research, 19(1), 231-240.

Zygouris, S., \& Tsolaki, M. (2014). Computerized cognitive testing for older adults: A review. American Journal of Alzheimer's Disease \& Other Dementias, 30(1), 13-28. doi: 10.1177/1533317514522852
Corresponding author Vaida Berneckè Lithuanian Sports University Ryto str. 11, Sutkūnai, Šiauliai area Lithuania Tel. +37068871470

Email vaidabernecke@gmail.com 